\title{
Aptamer-based biosensors for biomedical diagnostics
}

\author{
Wenhu Zhou ${ }^{1}$, Po-Jung Jimmy Huang ${ }^{2}$, Jinsong Ding ${ }^{1 *}$ and Juewen Liu ${ }^{1,2 *}$
}

1. School of Pharmaceutical Sciences, Central South University, Changsha 410013, Hunan Province, PR China

2. Department of Chemistry and Waterloo Institute for Nanotechnology, University of Waterloo, Waterloo, Ontario, N2L 3G1 Canada

*Corresponding authors: Jinsong Ding and Juewen Liu, Department of Pharmaceutics, School of Pharmaceutical Sciences, Central South University. Tongzipo Road \#172, Changsha 410013, Hunan Province, PR China. Tel.: + 86731 82650250. Fax: + 86731 82650442. E-mail: dingjs0221@ 163.com; and Department of Chemistry and Waterloo Institute for Nanotechnology, University of Waterloo, Waterloo, Ontario, N2L 3G1 Canada, e-mail: liujw@uwaterloo.ca. 


\begin{abstract}
Aptamers are single-stranded nucleic acids that selectively bind to target molecules. Most aptamers are obtained through a combinatorial biology technique called SELEX. Since aptamers can be isolated to bind to almost any molecule of choice, can be readily modified at arbitrary positions and they possess predictable secondary structures, this platform technology shows great promise in biosensor development. Over the past two decades, more than one thousand papers have been published on aptamer-based biosensors. Given this progress, the application of aptamer technology in biomedical diagnosis is still in a quite preliminary stage. Most previous work involves only a few model aptamers to demonstrate the sensing concept with limited biomedical impact. This Critical Review aims to summarize progresses that might enable practical applications of aptamer for biological samples. First, general sensing strategies based on the unique properties of aptamers are summarized. Each strategy can be coupled to various signaling methods. Among these, a few detection methods including fluorescence lifetime, flow cytometry, upconverting nanoparticles, nanoflare technology, magnetic resonance imaging, electronic aptamer-based sensors, and lateral flow devices have been discussed in more detail since they are more likely to work in a complex sample matrix. The current limitations of this field include the lack of high quality aptamers for clinically important targets. In addition, the aptamer technology has to be extensively tested in a clinical sample matrix to establish reliability and accuracy. Future directions are also speculated to overcome these challenges.
\end{abstract}




\section{Introduction}

Biomedical diagnosis is a central component of the modern healthcare system, allowing (early) detection of diseases and monitoring therapeutic progresses. ${ }^{1-6}$ Since a disease state is often associated with the deviation of certain molecular signatures from normal conditions, accurate and selective measurement of the structural and concentration change of disease marker molecules is a major goal of the current analytical chemistry. Disease markers can be found at a few different levels, including DNA, RNA, proteins and small molecule metabolites. ${ }^{7-9}$ Both analytical instruments and biosensors have been used in biomedical diagnosis. Instrumentation methods such as mass spectrometry and NMR can provide rich information not only about analyte concentration but also structure. In addition, multiple target molecules might be measured at the same time. However, sample pre-treatment is often required and a long turnaround time (often days) is needed to obtain the result since such assays cannot be performed on-site. Desirable diagnosis should provide immediate results on site during a patient visit or at home with a minimal sample volume and non-invasively. In this regard, biosensors have many operational advantages such as fast detection, ease-of-use, portability, cost-effectiveness and ease of mass production, which make them ideal choices to meet the growing needs for biomedical diagnostics. ${ }^{10-12}$

A biosensor contains two main components: a biological recognition element that detects the target molecule and a signaling component that converts the biological recognition into physically detectable signals. Recognition molecules are crucial for biosensors since their binding affinity and specificity determines the sensor performance. So far, a diverse range of recognition molecules have been employed. Antibodies have been the most commonly used probes since they can selectively bind a broad range of analytes with high affinity. The commercial availability of antibodies is another strong support for their research and development. However, antibodies also exhibit certain limitations. For instance, antibodies are sensitive to temperature and prone to irreversible denaturation. ${ }^{13}$ The 
production of antibodies often involves animals suffering batch-to-batch variation. In addition, antibodies have high molecular weight and it is difficult to achieve site-specific labeling. Finally, antibody-based assays often require immobilization and extensive washing, while it is difficult to carry out homogeneous assays. Therefore, it is highly desirable to seek alternative ligands as a new platform for biomedical diagnosis.

Since the early 1990s, aptamers have attracted tremendous attention. ${ }^{14,15}$ Aptamers refer to singlestranded nucleic acids that can fold into specific 3D structures and selectively bind to target molecules. Most aptamers are obtained through a combinatorial selection process called systematic evolution of ligands by exponential enrichment (SELEX). SELEX has resulted in many aptamers that can bind to a broad range of targets, including metal ions, small molecules, peptides, proteins, and even complextarget such as the whole cell and materials surfaces. Aptamers are attractive for biosensor development due to their small size, high stability (especially DNA aptamers), high binding affinity and specificity, and ease of modification. ${ }^{16,17}$ First, aptamers can in principle be selected for any given target, including those without soliciting immune responses or with high toxicity. Second, chemical synthesis of aptamers is well developed, leading to highly reproducible reagents that can be labeled at arbitrary positions with a variety of functional groups. Third, DNA aptamers are more stable than proteins and can be repeatedly used without losing their binding capability. Fourth, aptamers have little immunogenicity or toxicity. Finally, due to their small size, aptamers may achieve a higher density for immobilization and bind to epitopes that are not easily accessed by antibodies.

With these advantages, significant advances have been made on aptamer-based sensing. By a search of the ISI Web of Knowledge database, more than 1200 papers have been published as of November 2013 under the keywords of 'aptamer' and 'biosensor'; the number of papers has been growing exponentially (Figure 1A). This is also a global effort (Figure 1B). While a number of aptamer-based drugs and targeting molecules have entered clinical trials (see Table 1) and have even 
been approved, such as Macugen, few aptamer-based diagnostic products are on the market. Given the amount of knowledge accumulated in the past two decade, this is a good time to critically summarize this field and identify new solutions to move forward. Numerous review papers have already been published on various aspects of the aptamer biosensor field at different stages of development, ${ }^{4,16,18-28}$ and we do not intend to provide a comprehensive review here. In this Critical Review, we first briefly describe aptamer selection and general biosensor design strategies, keeping in mind biomedical diagnosis as the application goal. Following that, specific designs that are promising for clinical applications are discussed.
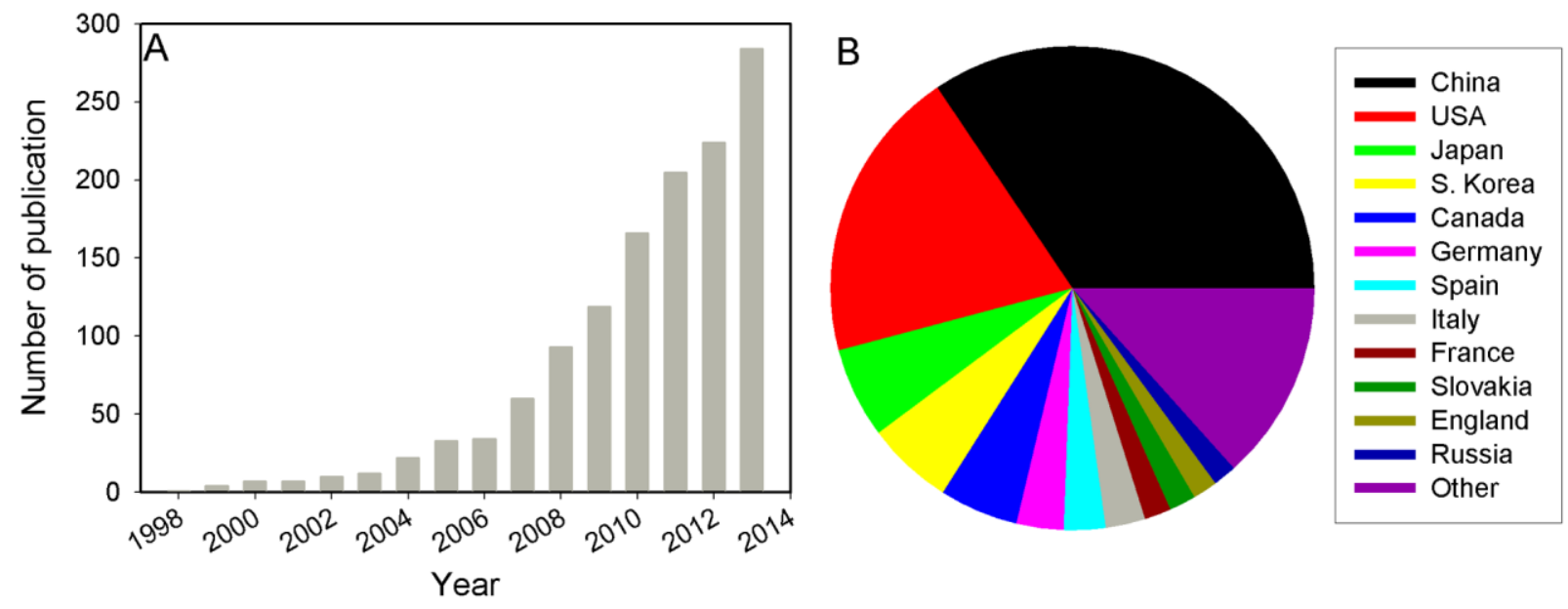

Figure 1. (A) The number of publications under the keywords of 'aptamer' and 'biosensor' from 1998 to November 2013. (B) The distribution of the publications from different countries. 
Table 1. Aptamers in Clinical Development. ( Source from http://www.clinicaltrials.gov and reference ${ }^{29,30}$ )

\begin{tabular}{|c|c|c|c|c|}
\hline Aptamer & Condition & Target & Phase & Identifier \\
\hline ARC1905 & $\begin{array}{c}\text { Age-related macular } \\
\text { degeneration }\end{array}$ & $\begin{array}{c}\text { Factor C5 of the } \\
\text { complement cascade }\end{array}$ & Phase I & $\begin{array}{l}\text { NCT00950638 } \\
\text { NCT00709527 }\end{array}$ \\
\hline E10030 & $\begin{array}{c}\text { Age-related macular } \\
\text { degeneration }\end{array}$ & $\begin{array}{l}\text { Platelet-derived growth } \\
\text { factor-B (PDGF-B) }\end{array}$ & $\begin{array}{l}\text { Phase I } \\
\text { Phase } \\
\text { III }\end{array}$ & $\begin{array}{l}\text { NCT01089517 } \\
\text { NCT00569140 } \\
\text { NCT01944839 } \\
\text { NCT01940900 }\end{array}$ \\
\hline EYE001 & $\begin{array}{c}\text { Macular Degeneration } \\
\text { Choroidal Hippel-Lindau } \\
\text { Disease }\end{array}$ & $\begin{array}{l}\text { Vascular endothelial } \\
\text { growth factor(VEGF) }\end{array}$ & $\begin{array}{l}\text { Phase } \\
\text { II/III } \\
\text { Phase I }\end{array}$ & $\begin{array}{l}\text { NCT00021736 } \\
\text { NCT00056199 }\end{array}$ \\
\hline $\begin{array}{c}\text { REG1 } \\
\text { (RB006/ RB007) }\end{array}$ & $\begin{array}{c}\text { Coronary Artery Disease } \\
\text { Acute Coronary Syndrome } \\
\text { Healthy }\end{array}$ & Factor IXa & $\begin{array}{l}\text { Phase II } \\
\text { Phase II } \\
\text { Phase I }\end{array}$ & $\begin{array}{l}\text { NCT00715455 } \\
\text { NCT00932100 } \\
\text { NCT00113997 }\end{array}$ \\
\hline EYE001 & Hippel-Lindau Disease & $\begin{array}{l}\text { Vascular endothelial } \\
\text { growth factor(VEGF) }\end{array}$ & Phase I & NCT00056199 \\
\hline AS1411 & Acute Myeloid Leukemia & Nucleolin & Phase II & NCT01034410 \\
\hline NOX-E36 & $\begin{array}{c}\text { Chronic Inflammatory } \\
\text { Diseases } \\
\text { Autologous stem cell }\end{array}$ & $\begin{array}{l}\text { Monocyte chemotactic } \\
\text { protein-1 (MCP-1) }\end{array}$ & Phase I & NCT00976729 \\
\hline NOX-A12 & $\begin{array}{c}\text { Transplantation } \\
\text { Hematopoietic Stem Cell } \\
\text { Transplantation }\end{array}$ & $\begin{array}{l}\text { Stromal cell-derived } \\
\text { factor-1 (SDF-1) }\end{array}$ & Phase I & $\begin{array}{l}\text { NCT00976378 } \\
\text { NCT01194934 }\end{array}$ \\
\hline ARC1779 & Von Willebrand Disease & $\begin{array}{c}\text { A1 domain of von } \\
\text { Willebrand Factor (vWF), }\end{array}$ & Phase II & $\begin{array}{l}\text { NCT00632242 } \\
\text { NCT00694785 }\end{array}$ \\
\hline $\begin{array}{l}\text { BAX499 } \\
(\text { ARC19499) }\end{array}$ & Hemophilia & $\begin{array}{l}\text { tissue factor pathway } \\
\text { inhibitor(TFPI) }\end{array}$ & Phase I & NCT01191372 \\
\hline NU172 & Heart Disease & Thrombin & Phase II & NCT00808964 \\
\hline
\end{tabular}

\section{Aptamer Selection.}

Since its inception in 1990, the majority of aptamers have been isolated using SELEX. ${ }^{31-35}$ In 2002 , the first naturally occurring aptamers known as riboswitches were found in the untranslated regions of many bacterial mRNA. ${ }^{36}$ Since riboswitches are made of RNA and are often quite large, they have not been widely used for sensing outside cells and will not be reviewed here. A typical SELEX scheme is presented in Figure 2, where a large random DNA or RNA library $\left(10^{13}-10^{15}\right)$ is subjected to an iterative process of in vitro selection and amplification. After mixing the library with the target molecule, a critical step is the separation of binding aptamers. Depending on the property of each target 
molecule, the separation strategy can be quite different. Small molecule targets are often covalently immobilized on a column and non-bound DNA can be washed away. Protein targets often involve a filter membrane to pass the unbound free DNA while retain the DNA/protein complex. For even larger targets such as cells, separation is achieved by centrifugation. The isolated binding DNA is amplified by PCR to seed the next round of selection. Numerous modifications have been made to improve the critical step: separation of binding aptamers from the unbound DNA, such as using capillary electrophoresis, ${ }^{37-40}$ microfluidic devices, ${ }^{41-45}$ AFM tips,${ }^{46}$ and magnetic beads. ${ }^{47}$

Given that hundreds of aptamers have already been isolated, there are still a number of issues to be addressed at the SELEX step. For small molecule targets, selections were often carried out by covalently attaching the target to a solid support. The resulting aptamers give low $\mu \mathrm{M} \mathrm{K}_{\mathrm{d}}$, while many riboswitches can bind targets at low $\mathrm{nM}$ affinity. One striking example is for guanine binding. Compared to the natural riboswitch with a $\mathrm{K}_{\mathrm{d}}$ of $5 \mathrm{nM},{ }^{48}$ a selected RNA aptamer exhibits a $\mathrm{K}_{\mathrm{d}}$ of 1.3 $\mu \mathrm{M}{ }^{49}$ This difference can be attributed to the inaccessibility of part of the target molecule during selection due to covalent immobilization and the larger size of the riboswitch allowing more complex binding structures. Membrane proteins interesting for biomedical diagnosis are often selected with purified outer membrane fragments. However, natural proteins might be quite different in folding with different glycosylation patterns. Furthermore, most selections are carried out in buffers different from the actual detection conditions. The change of $\mathrm{pH}$, ionic strength, temperature and the presence of matrix molecules can all adversely affect target binding. To address some of these problems, new selection strategies especially cell-SELEX ${ }^{50,51}$ and tissue-SELEX ${ }^{52}$ have been developed, providing new promising analytical reagents. 


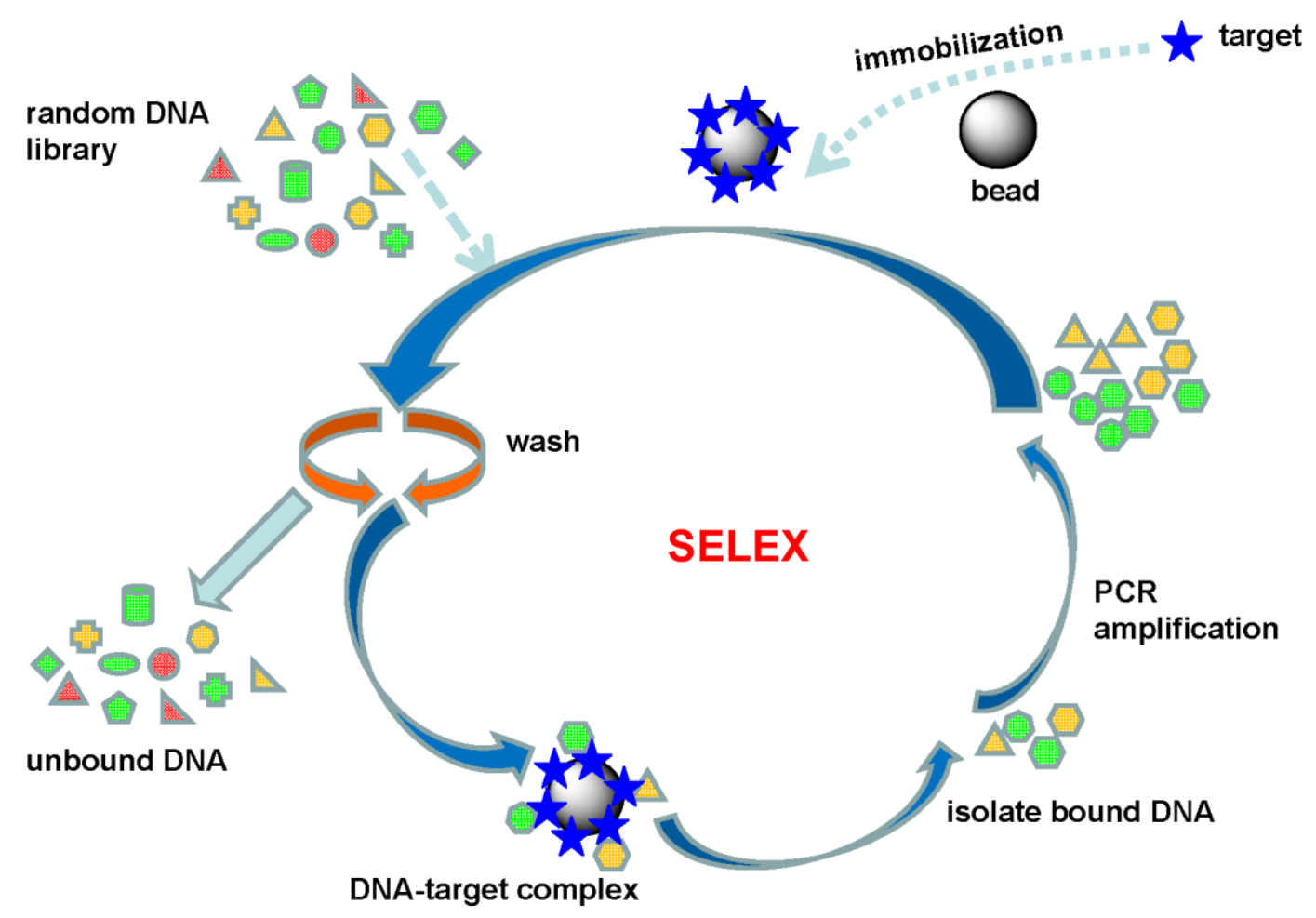

Figure 2. Isolation of aptamers using SELEX. In this example, the target molecule is immobilized on a bead to achieve separation.

\section{Biosensor design strategies.}

Once an aptamer sequence is known, an assay can be designed to measure its target molecule. Aptamers can be used in a similar way to antibodies for simple binding. But beyond that, many other assays unique to aptamers have been demonstrated. Most of them take advantage of the programmable property of nucleic acids. For example, a conformational change into a well-defined binding structure is often associated with aptamer binding. ${ }^{53}$ Until now, more than one thousand papers have been published on this topic. Since many comprehensive reviews are available for aptamer-based sensors, ${ }^{18,19,54-59}$ we only outline a few general design strategies. Each method can be coupled with various signaling methods. 
3.1. Simple binding based assays. Since aptamers are affinity ligands, they may replace antibodies in ELISA (enzyme-linked immunosorbent assay). ${ }^{60-62}$ Target binding to immobilized aptamers may also increase the mass or refractive index nearby the surface (Figure 3A). ${ }^{63-65}$ However, simple binding based assays require extensive washing. This is particularly important for biomedical samples since they often contain a high concentration of serum proteins. Another form of antibody-based assay is immunoprecipitation ${ }^{66}$ Since each antibody has multiple Fab arms and a target protein often has a few epitopes, the system can crosslink to precipitate. By attaching multiple aptamers to a nanoparticle, similar precipitants can also form with protein targets. ${ }^{67-70}$ If AuNPs are used, the color might change to blue or purple due to coupling of the gold surface plasmon band (Figure 3E).

A

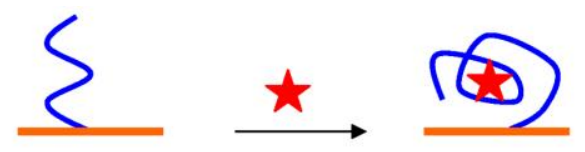

B

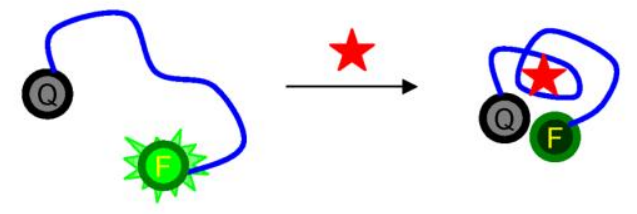

C

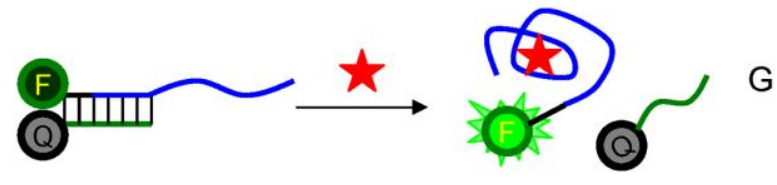

G
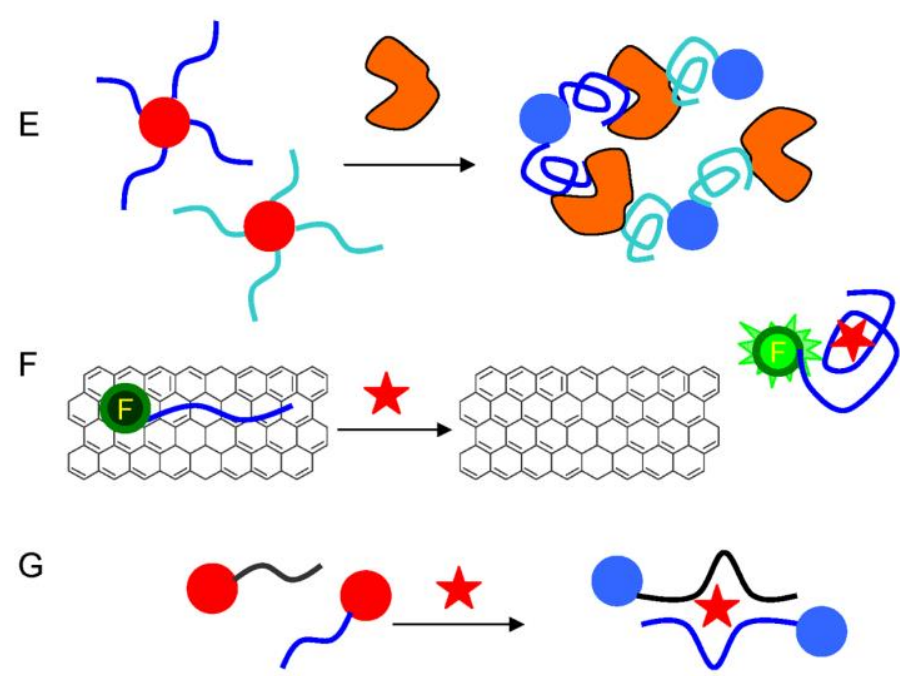

$\mathrm{H}$

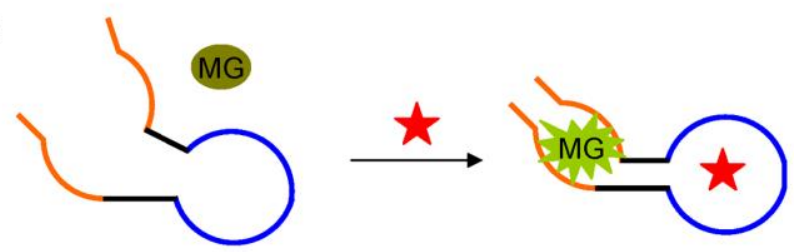

Figure 3. Various aptamer-based biosensor design strategies. (A) Simple binding-based assays. ELISA, mass or refractive index change induced by target binding can be tested on this platform. (B) FRETbased assays using binding induced aptamer conformational change. (C) Structure-switching aptamer design. (D) Self-assembly of split aptamer in the presence of target molecules. (E) Detection based on target-induced AuNP aggregates. (F) Using graphene oxide (GO) adsorbed probe DNA for detection. 
(G) Nanoparticle assembly induced by target binding of split aptamers. (H) Design of fused aptamer sensors using the MG for signaling.

3.2. Aptamer folding based sensors. While antibody binding does not change its global conformational, aptamers do. Such conformational changes may be used to avoid artifacts due to nonspecific binding. ${ }^{26}$ For example, aptamer conformational change may alter the local environment of an attached fluorophore. Based on this assumption, Ellington and co-workers test single fluorophore labeled aptamers. ${ }^{71}$ However, it is not straightforward to choose the most efficient labeling site and the amount of signal change is often quite modest. The performance of sensing is significantly improved by introducing an external quencher. In most designs, the two ends of an aptamer are labeled with a fluorophore and a quencher, respectively (Figure 3B). The fluorophore emission is thus sensitive to the end-to-end distance change. Such methods have been used to detect $\mathrm{K}^{+},{ }^{72}$ cocaine, ${ }^{73}$ adenosine/ATP, ${ }^{74}$ and proteins. ${ }^{75}$ In addition to using fluorophores, aptamer folding can also be detected using AuNPs. For example, folded aptamers cannot be easily adsorbed by AuNPs, while unfolded ones can be adsorbed to give better colloidal stability of AuNPs. ${ }^{76,77}$

3.3. Structure-switching signaling aptamers. Since an aptamer is also a piece of DNA, it can bind to its complementary DNA (cDNA). Therefore, an aptamer can be designed to switch between two distinct binding structures. One example is shown in Figure 3C, where a quencher-labeled cDNA is hybridized to a fluorophore-labeled aptamer. Initially the fluorescence is quenched. In the presence of the target, the quencher containing strand is released, leading to signal increase. ${ }^{78}$ Compared to the small end-to-end distance change within the aptamer, this method generates a much larger distance change and fluorescence enhancement. ${ }^{79-85}$ The fluorophore/quencher can be replaced by other signaling moieties such as electrode surfaces, ${ }^{86,87}$ quantum dots, ${ }^{88}$ or metal nanoparticles ${ }^{89}$ for other types of signal transduction. In addition to using cDNA to lock the initial aptamer conformation, a 
variation is to use an inorganic surface to adsorb the DNA probe. One of the most cited examples is graphene oxide (GO), which efficiently adsorbs ss-DNA and also serves as a fluorescence quencher. In the presence of the aptamer target, the adsorbed DNA can desorb to show fluorescence enhancement (Figure $3 \mathrm{~F}) .^{90}$

With an external quencher and a large change in distance upon target binding (e.g. from zero to infinite), the amount of signal increase is quite large. The downside of the structure-switching design, however, is the decreased aptamer binding affinity due to competition from the cDNA or inorganic surface. ${ }^{78}$ In addition, when the sensor system contains two pieces (Figure 3C), it is difficult to achieve continuous target monitoring since the released probe is unlikely to re-hybridize in a short time. Overall, this is a widely used signaling method unique for aptamer and it is next to impossible to have such rational structural changes incorporated into an antibody.

3.4. Split aptamer sensors. It is also possible to split an aptamer into two pieces. In the presence of target molecules, the two fragments can self-assemble to and change fluorescent signal. ${ }^{91,92}$ Yamamoto et al detected the HIV-1 Tat protein using this method. ${ }^{91}$ The aptamer sequence was divided into two pieces, with one piece in a hairpin structure containing a fluorophore and a quencher at the two ends. Without the target, the initial fluorescence was quenched. In the presence of Tat protein, the labeled fragment self-assembled with the other half to form a ternary complex, enhancing fluorescence due to separation of the fluorophore and quencher. Stojanovic et al also divided the anti-cocaine and antiadenosine aptamers into two halves, where successful sensing was achieved (Figure 3D). ${ }^{92}$ Pyrene excimer formation has also been used in this design. ${ }^{93} \mathrm{~A}$ variation of this is to immobilize each fragment on a AuNP to produce analyte-induced assembly (Figure 2F). ${ }^{94}$ In addition, split aptamers have been attached on fluid liposome surfaces. ${ }^{95}$ To engineer effective split aptamer sensors, the choice of splitting site is crucial. It is sometimes not straightforward to split an aptamer while still retaining its binding activity. ${ }^{96}$ In addition, the binding affinity decreases significantly since the originally dual- 
molecule reaction becomes a trimolecular reaction.

3.5. Fused aptamers. Opposite to the split aptamers, two aptamer modules can be rationally fused for sensing. One module is for target recognition and the other for signal generation. For example, Stojanovic and Kolpashchikov appended the malachite green (MG) aptamer to three different aptamers (ATP, FMN and theophylline). ${ }^{97} \mathrm{MG}$ is non-fluorescent by itself, but it becomes highly fluorescent upon binding to its RNA aptamer. ${ }^{98}$ In each case, MG binding was initially disfavored due to the lack of stable structures in the other aptamer (Figure $2 \mathrm{H}$ ). With the target analyte, the MG binding pocket is formed to produce fluorescence. This type of label-free signaling method might be useful for direct imaging and detection inside cells. ${ }^{99}$ Similar methods have been applied for detecting proteins and other analytes. ${ }^{100,101}$ Other ways of linking two aptamers for sensing have also been reported. ${ }^{102,103}$

In this section, we mainly used fluorescent assays to illustrate general sensor design strategies for aptamers. These strategies can be mounted on various signaling methods. Beyond fluorescence, colorimetric, electrochemical, Raman and magnetic resonance imaging have all been demonstrated. In the following section, we focus on a few specific methods that might be practically useful in biomedical diagnosis.

\section{Aptamer-based biosensors for biomedical diagnostics}

4.1. Practical considerations. It is quite interesting to note that while hundreds of aptamers have been selected and over one thousand sensing related papers have been published, only a handful of targets were used. In addition, few of these targets are of great clinical interest. This trend reflects a few difficulties faced by the field. The first challenge is the lack of high quality DNA aptamers for many clinically (and commercially) important targets, such as glucose, cholesterol and many other disease markers. A large number of the aptamer selections were carried out in companies and the detailed 
sequence information is not published. In addition, useful aptamers should be of sufficiently high quality, detecting target analytes at their physiologically related concentrations. The lack of high quality and high impact aptamers has confined the impact of this field mostly to academic research. Second, many reported aptamers lack detailed characterization, making it difficult for analytical chemists to do further developments. For rational biosensor design, the secondary structure of aptamers should be known. This is probably a major reason for the repeated use of the same model aptamers. The third difficulty comes from the accessibility of target molecules, especially proteins and specific cell lines. This has disallowed a broader community to study those aptamers, while the labs with these reagents may not be interested in analytical development. This calls for more collaborative work. Fourth, the sensors and assays have to work in complex sample matrix. Fortunately, it has been demonstrated on many occasions that aptamers still selectively recognize their targets and are relatively immune to nonspecific interactions in serum. ${ }^{104-106}$ This is not surprising since natural riboswitches work well in the cellular environment. Many of the sensors are demonstrated in simple buffers, while blood, serum, urine and saliva are the most common biomedical samples; they are complex with strong optical interference. For example, blood samples are highly viscous with a deep red color. Most visible light is scattered or absorbed, resulting in a very high background for optical detection. In addition, direct binding assays often suffer from non-specific binding due to other proteins in the sample. Fifth, the sampling methods also need to be considered. Blood samples need to be obtained with minimal invasiveness and the sensor has to work with a small sample volume. Finally, there is always a barrier and competition from the established assays such as those based on antibodies. To be widely accepted by industry, aptamer-based assays need to be extensively tested to establish their accuracy, reproducibility and user friendliness, avoiding multiple steps of liquid sample transfer and mixing. The cost needs to be lower than competing technologies. To date, a lot of efforts have been made to address these problems. We herein review examples that might be eventually useful for biomedical diagnosis. 
4.2 Time-resolved fluorescence. When monitoring proteins and metabolites in biological fluids, the background signal sometimes comes from the sample matrix. Instead of monitoring steady-state fluorescence intensity, one approach to decrease background interference is to use time-resolved fluorescence. Time-resolved fluorescence assays are based on the difference between the fluorescence lifetime of the detection signal and the nonspecific background (e.g. scattered and reflected excitation light or auto-fluorescence from the sample matrix). Usually the lifetime of background fluorescence is a few ns, which can be filtered using long lifetime probes such as pyrene. For example, Yang et al developed a wavelength-shifting dual-pyrene-labeled aptamer probe for detecting PDGF in biological fluids using both steady-state and time-resolved fluorescence. ${ }^{75}$ The aptamer was labeled with one pyrene at each end, and the two pyrenes are spatially separated without PDGF, resulting only in monomer emission at $\sim 400 \mathrm{~nm}$. The aptamer switches its emission to $485 \mathrm{~nm}$ (pyrene excimer) upon PDGF binding since the two pyrenes are then right next to each other. Importantly, the pyrene excimer has a much longer fluorescence lifetime (40 ns) than that of the background ( $5 \mathrm{~ns})$. This time-resolved detection allows for the elimination of most of the background fluorescence.

Zhang and co-workers argued that the fluorescence lifetime of the pyrene excimer is still too short to completely eliminate background signal. They introduced europium ions $\left(\mathrm{Eu}^{3+}\right)$ as the fluorophore since lanthanides have a much longer lifetime that can reach $\sim 1 \mathrm{~ms} .{ }^{107}$ To detect adenosine deaminase (ADA), a biotinylated adenosine aptamer is first immobilized on a streptavidin-coated plate surface in the presence of adenosine. Without ADA, adenosine is associated with the aptamer, inhibiting binding of the cDNA with the $\mathrm{Eu}^{3+}$ label. With $\mathrm{ADA}$, adenosine is converted to inosine that is not recognized by the aptamer. As a result, the cDNA is hybridized and $\mathrm{Eu}^{3+}$ is immobilized, allowing an enhanced lifetime signal to be detected. A detection limit of $2 \mathrm{U} \mathrm{L}^{-1}$ ADA was achieved, which can meet the clinical requirement of $\left(4 \mathrm{U} \mathrm{L}^{-1}\right)$. Importantly, this approach can be used to detect ADA in human serum quantitatively. Huang and co-workers reported another example of lifetime based assay for adenosine 
detection based on home-made $\mathrm{Eu}^{3+}$ complexes (ENT). ${ }^{108}$ In these examples, the probes were also immobilized for detection. While high sensitivity can be achieved, it required a lot of washing steps. Recently, Lu and co-workers also reported a $\mathrm{Tb}^{3+}$ complex for homogeneous time-gated fluorescence detection. The $\mathrm{Tb}^{3+}$ complex has a lifetime on the order of ms. Using a delay time of $50 \mu \mathrm{s}$, most interfering fluorescence was eliminated. ${ }^{109}$ This method detects adenosine in undiluted blood serum down to $60 \mu \mathrm{M}$, comparable with that achieved in clean buffers. While the physical principle of such detection methods is attractive, measurement of fluorescence lifetime requires more sophisticated hardware and than measuring steady-state fluorescence intensity, making on-site detection more challenging. In addition, many of the published examples involve heterogeneous reactions. Developing homogenous assays is likely to be an important future direction. ${ }^{28}$

4.3 Upconverting nanoparticles. Upconverting nanoparticles (UCNPs) convert a long wavelength excitation (often in the IR range) into shorter wavelength fluorescence (anti-Stokes emission). In this process, more than one photon needs to be absorbed before emission takes place. This anti-Stokes fluorescent property might be useful for bioassays conducted in complex matrices. ${ }^{110}$ First, IR light causes minimal photo damage to biological substances and less photobleaching. Second, IR light does not excite biological fluorophores that may be present in the sample matrix. Third, anti-Stokes fluorescence effectively reduces auto-fluorescence and light scattering, producing clean emission spectra with high signal-to-noise ratio. Finally, the synthesis of UCNPs is now mature and high quality particles can be routinely produced. It needs to be noted that the surface of UCNPs is often capped by hydrophobic ligands. These capping ligands are important not only for maintaining colloidal stability, but also for protecting the long lifetime luminescence of these particles. Since biosensing takes place in aqueous environments, various methods have been established for bioconjugation. ${ }^{111}$ Methods have also been developed to attach DNA to UCNPs. ${ }^{112,113}$ By now, UCNPs have been successfully applied to the detection of biomolecules such as proteins, ${ }^{114}$ DNA, ${ }^{115}$ and metal ions. ${ }^{116}$ 

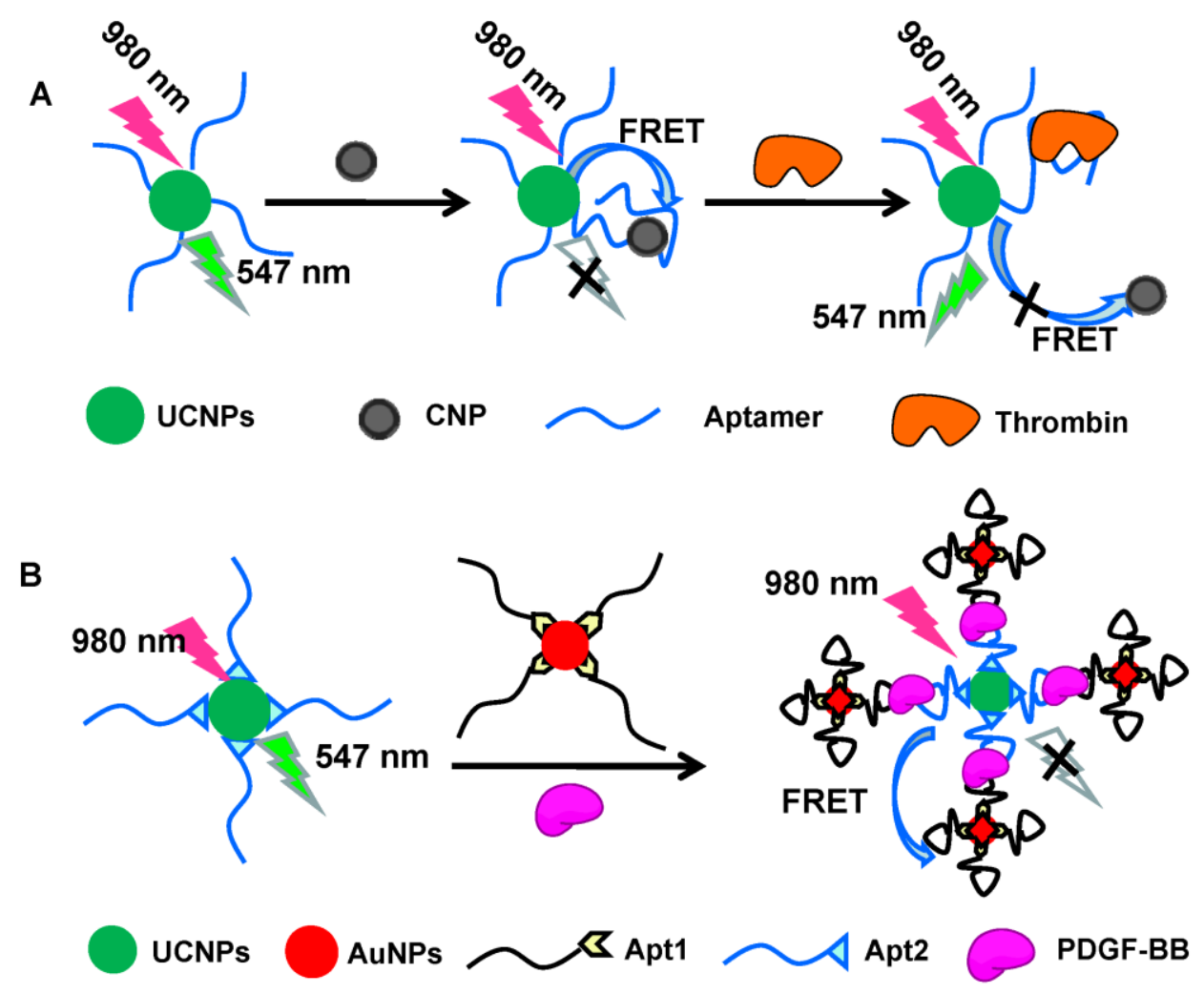

Figure 4. Sensing with UCNPs. (A) Thrombin sensor based on FRET from aptamer-modified UCNPs to CNPs. (B) Sandwich assay with aptamer-functionalized AuNPs and UCNPs for PDGF detection.

By using aptamer-functionalized NaYF4:Yb/Er UCNPs as the energy donor and carbon nanoparticles (CNP) as the energy acceptor, Wang et al developed a FRET-based biosensor for thrombin (Figure 4A). ${ }^{117}$ The absorption spectrum of CNP overlaps well with the emission spectrum of the UCNPs. Without thrombin, the aptamer-UCNP conjugate was brought in close proximity to the CNPs through $\pi-\pi$ stacking and hydrophobic interactions between DNA and CNP, leading to quenched emission. In the presence of thrombin, the aptamer formed a G-quadruplex structure, decreasing the interaction with CNPs and restoring fluorescence. The sensor has a dynamic range from 0.5 to $20 \mathrm{nM}$ with a detection limit of $0.18 \mathrm{nM}$ thrombin. Importantly, the same linear range was obtained in human serum, indicating high robustness of the sensor.

Lin et al developed a biosensor for PDGF-BB in blood serum based on FRET from UCNPs to 
AuNPs (Figure 4B). ${ }^{118}$ In this system, the same aptamer was modified with either a thiol group to attach to AuNPs (Apt1-AuNPs) or an amine group to attach to UCNPs (Apt2-UCNPs). Since each PDGF-BB can bind to two aptamers, it is possible to form a sandwich structure with these two NPs, leading to FRET-based quenching. A detection limit of $10 \mathrm{nM}$ was reported. Meanwhile, with this method, PDGF-BB in the blood serum of lymphoma patients can be detected directly with good stability and selectivity. While attaching aptamers to UCNPs is still in its early stage of development, the unique physical properties of these particles are likely to make a major impact in biomedical diagnosis. The current sensor designs are mostly for proof-of-concept, and more work is needed to establish the long-term stability of their DNA conjugates.

4.4 Magnetic resonance imaging. Magnetic resonance imaging (MRI) is one of the most powerful non-invasive imaging modalities for disease diagnosis, providing three-dimensional examination of biological events in living organisms. MRI is based on the relaxation property of protons in an external magnetic field, providing contrast in different tissues. Sensing based on MRI is of particular interest because it can be easily realized under in vivo conditions. To enhance the quality of MRI, many contrast agents have been developed. Among these, superparamagnetic iron oxide nanoparticles (SPION) are very attractive due to high biocompatibility and efficiency in dephasing the spins of water protons. Lu and co-workers developed a strategy for adenosine detection in human serum using MRI. In their report, SPION functionalized with either $3^{\prime}$ or $5^{\prime}$ thiol-modified DNA were assembled with a linker DNA. In the absence of adenosine, the nanoparticles were clustered by the linker, while after addition of the target, the particles disassembled to give a higher $\mathrm{T} 2$ value. By monitoring the $\mathrm{T} 2$ relaxation time of samples with different adenosine concentrations, quantitative analysis was achieved. The biosensor retains its activity in human serum (10\%) with high selectivity. ${ }^{106}$ Similar strategies have also been applied for detecting thrombin in human serum. ${ }^{119}$ Hwang et al reported conjugation of a nucleolin-targeting aptamer (named AS1411) to cobalt-ferrite NPs with a silica shell, where in vivo 
imaging of cancer tissues was demonstrated. ${ }^{120}$ Aptamer-assisted MRI has also been reported with other magnetic nanoparticles or aptamers. ${ }^{121,122}$

In another approach, a DNA aptamer-conjugated $\mathrm{Gd}^{3+}$ complex was developed. Gadolinium compounds are widely used as MRI contrast agents, but they often lack specificity for metabolites. In this report, the sensing system consists of an adenosine aptamer attached to a streptavidin, and a DOTA-Gd-containing DNA strand that hybridized to a fragment of the aptamer. The rotational correlation time of the gadolinium compound is long for the hybridized complex due to its high molecular weight. In the presence of adenosine, the Gd-bearing strand dissociates, decreasing the molecular weight of the Gd complex and increasing relaxivity. The detection was also demonstrated in $10 \%$ human serum. ${ }^{123}$ Compared to SPION-based MRI contrast agents, gadolinium-based agents are smaller in size and easier for intracellular imaging. A limitation of current MRI contrast agents is that high concentrations are required, and aptamer attachment might help solve this issue by increase specificity. More in vivo work is needed to further demonstrate its potential.

4.5. Nanoflare technology. While the previously reviewed examples detect extracellular targets, intracellular detection is also desirable. However, there are a few extra difficulties. First, cells do not directly internalize nucleic acid probes. In addition, DNA probes are prone to nuclease degradation. Finally, measurement of fluorescence in cells often requires a microscope or flow cytometer. Despite these difficulties, one such technology called 'nano-flares', has been commercialized to detect mRNA. ${ }^{124,125}$ Nano-flares refer to a special fluorescent DNA-AuNP conjugate as shown in Figure 3C, except that the quencher is replaced by AuNPs. Compared to molecular dark quenchers (such as Dabcyl), AuNPs have better quenching efficiency and longer quenching range. ${ }^{126,127}$ In the presence of target mRNA, the fluorescent DNA probe (flare) is displaced to generate signal. The success of nanoflare takes advantage of the unique properties of DNA-AuNPs such as enhanced target binding affinity, the ability to enter cells, resistance to enzymatic degradation and enhanced colloidal stability. ${ }^{128}$ In a 
follow-up work, Mirkin and coworkers developed an aptamer nano-flare probe for directly quantifying ATP in living cells. ${ }^{129}$ In this system, a AuNP core is decorated with a dense layer of chemisorbed ATP aptamer. A fluorophore-labeled DNA reporter is hybridized to the aptamer. Upon ATP binding, the DNA reporter is dissociated, resulting in fluorescence increase. This nano-flare sensor is sensitive to physiologically relevant changes in ATP concentrations (0.1-3 mM) with high selectivity.

The AuNP platform can also be engineered to detect multiple analytes based on different fluorescent probes. ${ }^{130}$ In a recent report, a multiplexed nanoflare was constructed to detect two distinct mRNA targets inside living cells. In addition, this design may also take into account the influence of cell-to-cell variation, such as differences in NP uptake. For example, one probe can be used for monitoring the target and the other may serve as an internal control for standardization. ${ }^{131}$ Following these results, a sensor for simultaneous detection of three tumor-related mRNA in live cells was reported. $^{132}$

4.6 Flow cytometry. Flow cytometry employs fluorescence and light scattering for analyzing individual cells and particles in a capillary; it is often used for blood analysis in hospitals. With the small capillary, the path length of light is significantly reduced and interference from the sample matrix might also decrease. Compared to other methods such as dialysis, electrophoresis, centrifugation, immobilization, and chromatography, flow cytometry is an excellent approach for separating fluorescence detection from the serum sample matrix as it achieves separation without actually performing an additional separation step. A few examples have been reported for aptamer-based cell, ${ }^{133}$ and small-molecule detection. ${ }^{134}$ Huang et al combined flow cytometry with aptamer-functionalized magnetic microparticles (MMPs) for detecting adenosine in serum using the structure switching aptamer design: a quencher labeled DNA is released in the presence of adenosine, leading to fluorescence increase. ${ }^{134}$ The flow cytometer serves to isolate the MMP sensors from the serum and detects the fluorescent signal. In particular, the sample volume for adenosine detection can be as low as 
$10 \mu \mathrm{L}$, which is desirable for practical applications. The detection limit of adenosine in $90 \%$ serum is $0.2 \mathrm{mM}$.

Since flow cytometers are designed for cell analysis, aptamer binding to cell surface proteins has been extensively studied using flow cytometry. ${ }^{135,136}$ In these studies, aptamers are tagged with a fluorophore and target cells can be separated even in a complex sample matrix. For example, Tan and co-workers labeled both fluorescent and magnetic NPs with an aptamer targeting a leukemia cell. The cells can be enriched using the magnetic NPs from whole blood samples and then detected based on the fluorescence using flow cytometry. ${ }^{136}$ Flow cytometry is currently used in many hospitals for blood sample analysis. Therefore, this appears to be a viable platform for developing aptamer-based diagnosis. To make it available at a lower cost and for smaller sample volume, microfluidic devices are likely to be incorporated as a future direction. ${ }^{137}$

4.7 Electrochemistry sensors. The biosensor field is growing on the success story of glucose meters, which detect blood glucose using electrochemistry detection. Clearly, the sample matrix effect has been nicely resolved using this platform. DNA-based electrochemical detection in complex sample matrices such as blood serum, ${ }^{105}$ crude cellular extracts, ${ }^{138}$ and soil extracts ${ }^{139}$ has already been demonstrated. Compared to the numerous optical interfering species, the number of electrochemically active species in the potential range of most employed redox labels is quite small. ${ }^{140}$ Electrochemical detection can be readily miniaturized and automated with high detection speed, low cost and minimal sample consumption. This platform does not require a light source, high-voltage power supplies or other sophisticated equipment. Given these advantages, electrochemistry sensors appear well suited for practical applications.

A large number of papers and reviews have been published regarding in this field. ${ }^{19,26,141}$ We only review a few examples here. Xiao et al developed a sensitive, selective and reusable 'signal-off' electrochemical aptamer-based sensor for thrombin (Figure 5A). ${ }^{142}$ The sensor is constructed by 
covalently immobilizing a methylene blue (MB) label on the thrombin-binding aptamer to a gold electrode through a thiol group. Since the aptamer chain is initially flexible in the absence of thrombin, the MB label is close to the electrode surface to achieve high electron-transfer efficiency. Upon target binding, the aptamer folds into its inherent binding structure, inhibiting electron transfer. The sensor detects down to $6.4 \mathrm{nM}$ thrombin.

The signal-off property is undesirable since it is more susceptible to background variation and the room for signal change is also small. A 'signal-on' approach for direct platelet-derived growth factor (PDGF) detection in blood serum was reported (Figure 5B). ${ }^{86} \mathrm{~A} \mathrm{MB}$ molecule was labeled at the $3{ }^{\prime}$-end of the PDGF aptamer, and a thiol group was modified at its $5^{\prime}$-end to attach to the gold electrode. In the absence of the target, the MB label is relatively far away from the electrode surface. PDGF binding induces a conformational change and the aptamer forms a stable three-way junction holding the MB label close to the electrode, enhancing electron transfer. This method could detect up to $10 \mathrm{nM}$ PDGF with a detection limit of $50 \mathrm{pM}$.

Further developments in this field include the use of microfluidic sensor chips to achieve continuous, real-time and high throughput automated detection. ${ }^{140}$ Rowe and co-workers developed a reusable aptamer-based electrochemical array platform to quickly detect $(<10 \mathrm{~s})$ aminoglycoside antibiotics in blood samples in order to prevent overdosage or side-effects. ${ }^{143}$ Ultrafiltration was used to remove nuclease to increase the RNA stability. While this pre-treatment step slows the overall workflow of the sensor, the sensor detects aminoglycoside at clinically relevant concentrations $(2-6 \mu \mathrm{M})$ in less than $30 \mathrm{~min}$ and requires only an inexpensive, desktop centrifuge. With the demonstrated examples, electrochemical detection is likely to be a viable means for biomedical diagnosis. An interesting recent development is the use of personal glucose meters to work with aptamer-based reagents. ${ }^{144,145}$ 

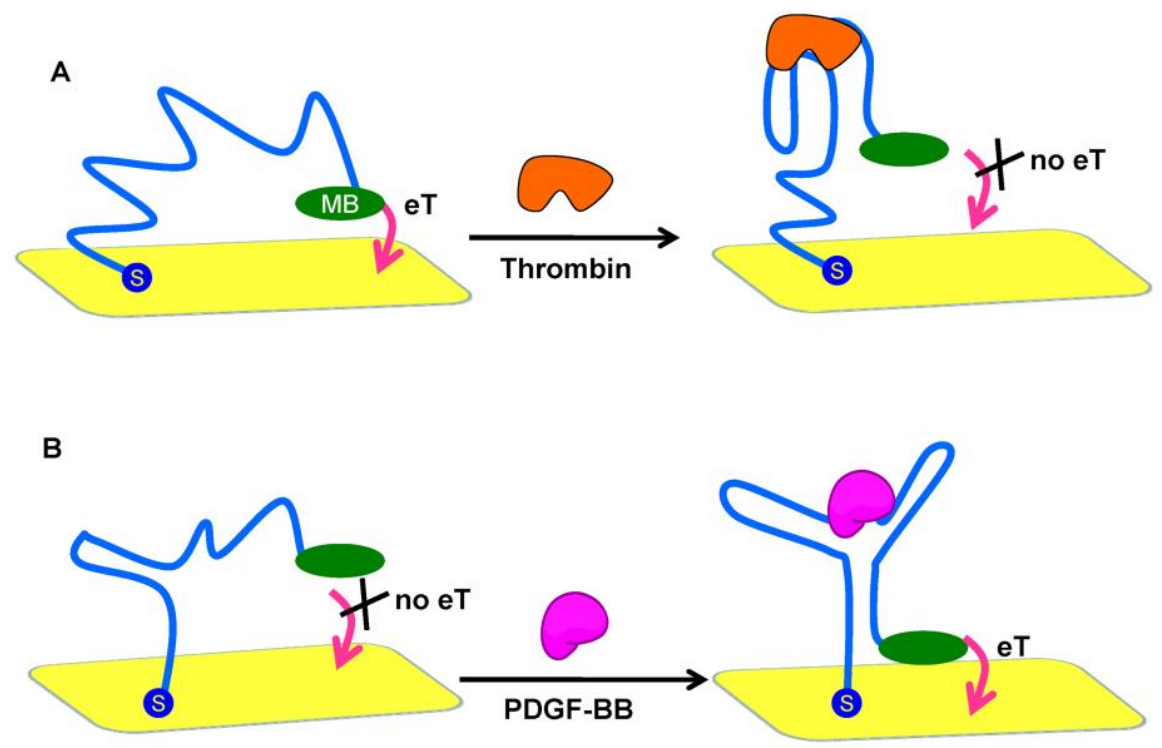

Figure 5. Electrochemical sensors involving aptamers. (A) 'Signal-off' electrochemical biosensor for thrombin detection. (B) 'Signal-on' electrochemical biosensor for PDGF detection. The aptamer probes are immobilized on gold electrode surface via the thiol labels.

4.8 Lateral flow devices. Pregnancy test strips are another success story of biosensors, which are based on the lateral flow technology. Lateral flow technology is a popular platform because of its low development cost and ease of use. While this platform has been developed to detect numerous targets using antibodies, aptamers have been recently tested as well. Using aptamer-linked AuNPs, Lu and coworker developed a simple device composed of four overlapping pads placed on a backing: a wicking pad, a glass fiber conjugation pad, a membrane, and an absorption pad (Figure 6A). ${ }^{146}$ The aptamerlinked and biotin-labeled AuNP aggregates were spotted on the conjugation pad, and streptavidin was immobilized on the membrane as a thin line to capture biotinylated AuNPs. When the wicking pad of the device is dipped into a solution containing adenosine, the AuNPs are disassembled and migrate along the membrane to be captured, forming a red line. Otherwise, the aggregated AuNPs are too large to move. Similarly, a cocaine sensitive device was prepared and it performed well in human blood 
serum.

A

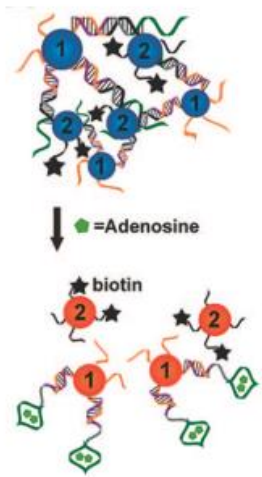

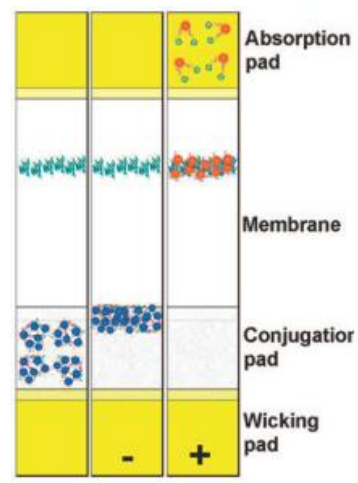

B

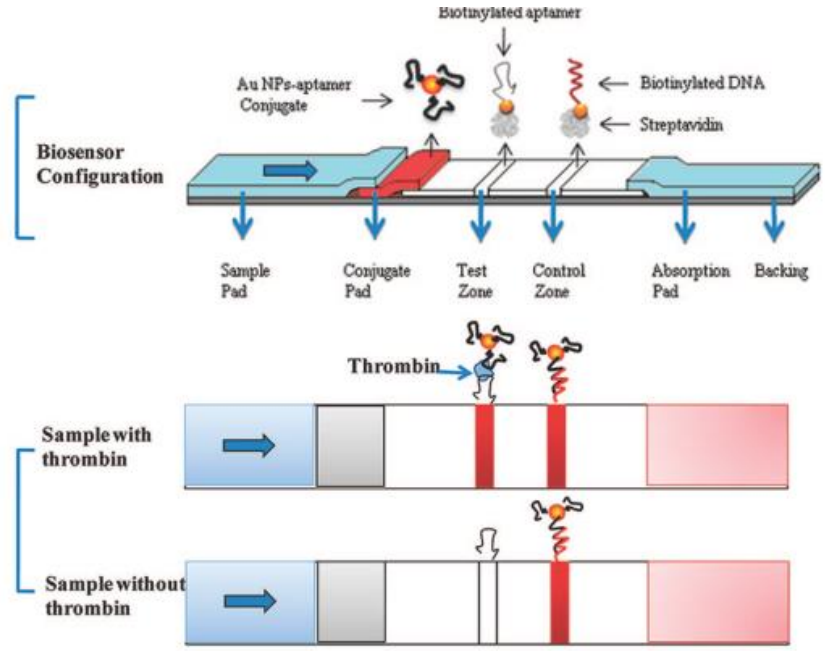

Figure 6. (A) Aptamer/AuNP-based lateral flow device. Left: adenosine-induced disassembly of AuNPs. Biotin is denoted as a black star. Right: schematics of lateral flow devices loaded with assembled nanoparticles (on the conjugation pad) and streptavidin (on the membrane) before use (left strip), in a negative (middle strip), or a positive (right strip) test. Without adenosine, the aggregated AuNPs cannot migrate on the membrane (Reproduced with permission from reference. ${ }^{146}$ Copyright 2006, Wiley-VCH) (B) Design principle of lateral flow sensor for thrombin detection. (Reproduced with permission from reference. ${ }^{147}$ Copyright 2009, American Chemical Society.)

$\mathrm{Xu}$ and co-workers designed a dry-reagent lateral flow biosensor for visual detection of thrombin within 10 min using aptamer-functionalized AuNPs (Figure 6B). ${ }^{147}$ When dipped into a solution containing thrombin, thrombin will move along the device and bind to aptamer-functionalized AuNPs. This complex can continue to migrate along the strip and be captured by the secondary aptamer immobilized on the test zone (note that thrombin has two aptamer binding sites). AuNPs passing the first capture line are then captured by the immobilized cDNA, forming a control line. The dynamic range of thrombin was 5-100 $\mathrm{nM}$, and detection limit was $2.5 \mathrm{nM}$. This study also compared with antibody-based strips, where the aptamer strips exhibited similar sensitivity and are even better 
specificity. The sensor was also capable of detection in human plasma samples. A few other assay formats involving bioactive paper and related flow technology have also been reported. ${ }^{148-150}$ Due to its simplicity (in fabrication and for use), lateral flow technology is one of the most successful platforms for developing bioanalytical assays. We speculate that this might be one of the first platforms for aptamer-based diagnosis to be commercialized. To achieve this, the long-term stability of DNA conjugates and their flow property need to be fully studied and optimized with an important target.

4.9. Other sensing methods. Aside from the strategies reviewed above, a number of other spectroscopic techniques also show promise in biomedical diagnosis. For example, colorimetric assays are attractive for its simplicity in detection. ${ }^{88,151}$ Using horseradish peroxidase for signal production and amplification is a routine method in immunoassays. Interestingly, G-quadruplex DNA with a hemin cofactor also shows peroxidase activity. ${ }^{152}$ Linking aptamers to such DNA has produced biosensors in both homogeneous and immobilized format. ${ }^{153-155}$ For such optical detection to work in complex biological samples, the sensor needs to be immobilized so that extensive washing can be carried out to minimize background interference. Surface plasmon resonance (SPR) is a highly sensitive method for measuring binding on gold surface. ${ }^{156}$ In this method, binding causes a change in the refractive index near the gold surface, which modulates its resonance angle. SPR has been applied to aptamer-based detection for detecting serum proteins such as vascular endothelial growth factor (VEGF) down to 1 pM. ${ }^{63}$ In the SPR assay format, the probe needs to be immobilized and the assays are carried out in the heterogeneous format with the advantage of achieving washing and signal amplification. The SPR technology will have more impact by developing portable instruments to reduce the cost. Other methods such as localized surface plasmon resonance (LSPR), ${ }^{157}$ and surface enhanced Raman scattering (SERS) have been coupled with aptamers for sensing. ${ }^{158}$ Their applications in complex samples have yet to be fully developed. 


\section{Summary and future directions.}

In the past two decades, the development of aptamer for analytical chemistry is quite remarkable. Aptamers have been shown to be versatile and effective as molecular probes for molecular recognition. At the same time, numerous methods have been demonstrated to convert aptamer binding into physically detectable signals. In many reports, aptamers detect proteins and small molecules with high sensitivity and selectivity, comparable to and sometimes even better than those available for antibodybased assays. ${ }^{147,159,160}$ Similar to antibodies, aptamers are also a platform technology, making them useful to meet the growing need of detecting emerging target molecules.

Despite these progresses, clinical applications of aptamer-based biosensors for are still lacking. As pointed out in this review, a number of issues need to be solved before aptamers can make clinical impacts. Addressing these problems will become a major part of the future direction. 1) One of the main bottlenecks is the lack of high quality aptamers for clinically important targets. So far the majority of the work is carried out with DNA aptamers. To improve the binding property, it is worthwhile to look into RNA aptamers. There are many excellent RNA aptamers obtained through SELEX and also many riboswitches that can be potentially harnessed as biosensor components. In particular, riboswitches already detect important metabolites in physiologically relevant conditions and concentrations. Pioneering work in this regard has already been carried out. ${ }^{82,161-163}$ The technical problems involve the synthesis of longer RNA (more than 50 bases). RNA aptamers are often obtained from reverse transcription and it is difficult to label them. Maintaining RNA aptamer stability is also a challenge, which might be addressed by entrapping them in various materials. ${ }^{164}$ Another way to improve aptamer affinity is to introduce modified bases, which has already been practiced for many years for the purpose of improving RNA stability and binding affinity towards certain chemical groups. ${ }^{165}$ The amount of analytical work is still limited, which might relate to the high cost of probe 
synthesis and difficulty of labelling. We expect that cell-SELEX, tissue-SELEX and other advances will continue to be made to obtain aptamers suitable for real diagnosis conditions. 2) To make real impacts, efforts are to be focused on clinically important targets. Glucose detection still dominates the current biosensor field. To compete with the more established antibodies and protein enzymes, a few successful examples need to be demonstrated for aptamers. There are numerous clinical targets and the community may need to shift the focus from the proof-of-concept to real applications. For example, human epidermal growth factor receptor 2 (HER2) is regarded as a main prognostic or as a therapypredictive marker for breast cancer. ${ }^{110}$ Patients expressing high levels of the HER2 biomarker can be effectively treated with Herceptin. Monitoring HER2 is important because of its association with very aggressive types of breast cancer. ${ }^{111}$ Both RNA aptamers $\left(\mathrm{K}_{\mathrm{d}} \text { of } 3.5 \mathrm{nM}\right)^{113}$ and DNA aptamers $\left(\mathrm{K}_{\mathrm{d}}\right.$ of $18.9 \mathrm{nM}$ ) have been selected. ${ }^{114}$ More detailed characterizations are needed before they can be applied for biosensor development. 3) Recently, the nano-flare technology has been commercialized and many AuNP-conjugated probes can be purchased through Millipore. Although they do not directly detect aptamer targets, there are reports of using aptamer/AuNPs for cellular detection. Apparently, the use of AuNP is crucial for probe stability and assisting cell penetration. Aside from AuNPs, aptamers have been attached to many other types of materials and this could provide certain advantages for biomedical diagnosis. ${ }^{58}$ For example, immobilizing aptamers in hydrogels might also be a good way to filter interfering species. ${ }^{166-169}$ 4) We have reviewed a few detection methods that show promise for biomedical diagnosis. Keeping the sample matrix in mind, these detection methods need to be refined and validated to be clinically useful. 5) Unlike antibodies, DNA is highly negatively charged, making non-specific electrostatic interaction easy to take place. Since DNA probes are often immobilized on a surface to achieve detection, fundamental work is needed to understand the surface interaction between DNA, surface and target proteins in a complex sample matrix. ${ }^{170}$ Fundamental understanding of aptamer-target binding interactions in terms of binding affinity, aptamer secondary structure, and $\mathrm{K}_{\text {on }} / \mathrm{K}_{\text {off }}$ is also crucial, which will lead to improved utilization of aptamers for biosensors. 6) Finally, 
one strategy to address the sensitivity problem is to perform signal amplification. To achieve this goal, a large number of methodologies have already been employed, such as using metallic nanoparticles, ${ }^{67}$ quantum dots, ${ }^{171-173}$ DNA machines, ${ }^{154,174-176} \mathrm{PCR},{ }^{177}$ and rolling circle amplification (RCA). ${ }^{178}$ An interesting concept, called binding induced self-assembly, takes advantage of proximity or increased local concentration. In these systems, protein binding can be converted to DNA assembly with signal

amplification. ${ }^{179}$ This also allows ultrahigh sensitivity. ${ }^{180-182}$ It is important to couple these methods in a practically feasible format for biomedical diagnosis. Addressing these challenges will fuel the growth of the aptamer field in the future.

\section{Acknowledgement}

Funding for this work is from the University of Waterloo, NSERC of Canada and Foundation for Shenghua Scholar of Central South University.

\section{References}

1 A. P. F. Turner, Science, 2000, 290, 1315.

2 N. L. Rosi and C. A. Mirkin, Chem. Rev., 2005, 105, 1547.

3 E. Katz and I. Willner, Angew. Chem., Int. Ed., 2004, 43, 6042.

$4 \quad$ J. Liu, Z. Cao and Y. Lu, Chem. Rev., 2009, 109, 1948.

5 K. M. Wang, Z. W. Tang, C. Y. J. Yang, Y. M. Kim, X. H. Fang, W. Li, Y. R. Wu, C. D. Medley, Z. H. Cao, J. Li, P. Colon, H. Lin and W. H. Tan, Angew. Chem. Int. Ed., 2009, 48, 856.

6 Y. Du, B. L. Li and E. K. Wang, Acc. Chem. Res., 2013, 46, 203.

7 S. M. Nie, Y. Xing, G. J. Kim and J. W. Simons, in Annu. Rev. Biomed. Eng., 2007, pp. 257.

8 N. B. La Thangue and D. J. Kerr, Nat. Rev. Clin. Oncol., 2011, 8, 587.

9 G. Ploussard and A. de la Taille, Nat. Rev. Urol., 2010, 7, 101. 
B. Strehlitz, N. Nikolaus and R. Stoltenburg, Sensors, 2008, 8, 4296.

11 K. A. Willets and R. P. Van Duyne, in Annu. Rev. Phys. Chem., 2007, pp. 267.

12 J. Wang, Electroanalysis, 2005, 17, 7.

13 S. D. Jayasena, Clin. Chem, 1999, 45, 1628.

14 C. Tuerk and L. Gold, Science, 1990, 249, 505.

15 A. D. Ellington and J. W. Szostak, Nature, 1990, 346, 818.

16 T. Mairal, V. C. Ozalp, P. L. Sanchez, M. Mir, I. Katakis and C. K. O'Sullivan, Anal. Bioanal. Chem., 2008, 390, 989.

17 J. L. Wang, R. J. Lv, J. J. Xu, D. K. Xu and H. Y. Chen, Anal. Bioanal. Chem., 2008, 390, 1059.

18 S. Tombelli, A. Minunni and A. Mascini, Biosens. Bioelectron., 2005, 20, 2424.

19 I. Willner and M. Zayats, Angew. Chem., Int. Ed., 2007, 46, 6408.

20 D. Li, S. P. Song and C. H. Fan, Acc. Chem. Res., 2010, 43, 631.

21 N. K. Navani and Y. Li, Curr. Opin. Chem. Biol., 2006, 10, 272.

22 R. R. Breaker, Curr. Opin. Biotechnol., 2002, 13, 31.

23 E. J. Cho, J.-W. Lee and A. D. Ellington, Annu. Rev. Anal. Chem., 2009, 2, 241.

24 C. K. O'Sullivan, Anal. Bioanal. Chem., 2002, 372, 44.

25 K. Sefah, J. A. Phillips, X. Xiong, L. Meng, D. Van Simaeys, H. Chen, J. Martin and W. Tan, Analyst, 2009, 134, 1765.

26 A. A. Lubin and K. W. Plaxco, Acc. Chem. Res., 2010, 43, 496.

27 M. Famulok, J. S. Hartig and G. Mayer, Chem. Rev., 2007, 107, 3715.

28 H. Zhang, F. Li, B. Dever, X.-F. Li and X. C. Le, Chem. Rev., 2013, 113, 2812.

29 X. Ni, M. Castanares, A. Mukherjee and S. E. Lupold, Curr. Med. Chem., 2011, 18, 4206.

30 P. Sundaram, H. Kurniawan, M. E. Byrne and J. Wower, Eur. J. Pharm. Sci., 2013, 48, 259.

31 D. S. Wilson and J. W. Szostak, Annu. Rev. Biochem., 1999, 68, 611.

32 L. Gold, B. Polisky, O. Uhlenbeck and M. Yarus, Annu. Rev. Biochem., 1995, 64, 763. 
G. F. Joyce, W. C. Still and K. T. Chapman, Curr. Opin. Chem. Biol., 1997, 1, 3.

S. E. Osborne and A. D. Ellington, Chem. Rev., 1997, 97, 349.

W. Winkler, A. Nahvi and R. R. Breaker, Nature, 2002, 419, 952.

M. Berezovski, M. Musheev, A. Drabovich and S. N. Krylov, J. Am. Chem. Soc., 2006, 128, 1410.

A. Drabovich, M. Berezovski and S. N. Krylov, J. Am. Chem. Soc., 2005, 127, 11224.

S. D. Mendonsa and M. T. Bowser, J. Am. Chem. Soc., 2005, 127, 9382.

S. D. Mendonsa and M. T. Bowser, J. Am. Chem. Soc., 2004, 126, 20.

J. R. Qian, X. H. Lou, Y. T. Zhang, Y. Xiao and H. T. Soh, Anal. Chem., 2009, 81, 5490.

S. S. Oh, K. M. Ahmad, M. Cho, S. Kim, Y. Xiao and H. T. Soh, Anal. Chem., 2011, 83, 6883.

S.-m. Park, J.-Y. Ahn, M. Jo, D.-k. Lee, J. T. Lis, H. G. Craighead and S. Kim, Lab Chip, 2009, 9, 1206.

M. Jing and M. T. Bowser, Lab Chip, 2011, 11, 3703.

X. Lou, J. Qian, Y. Xiao, L. Viel, A. E. Gerdon, E. T. Lagally, P. Atzberger, T. M. Tarasow, A. J. Heeger and H. T. Soh, Proc. Natl. Acad. Sci. U.S.A., 2009, 106, 2989.

Y. Miyachi, N. Shimizu, C. Ogino and A. Kondo, Nucleic Acids Res., 2010, 38, e21.

R. Stoltenburg, C. Reinemann and B. Strehlitz, Anal. Bioanal. Chem., 2005, 383, 83.

D. Kiga, Y. Futamura, K. Sakamoto and S. Yokoyama, Nucleic Acids Res., 1998, $26,1755$.

51 X. H. Fang and W. H. Tan, Acc. Chem. Res., 2010, 43, 48.

Chem. Biol., 2010, 6, 22.

53 T. Hermann and D. J. Patel, Science, 2000, 287, 820. 
W. Zhao, M. A. Brook and Y. Li, ChemBioChem, 2008, 9, 2363.

Y. W. Lin, C. C. Huang and H. T. Chang, Analyst, 2011, 136, 863.

56 Y. J. Song, W. L. Wei and X. G. Qu, Adv. Mater., 2011, 23, 4215.

57 A. B. Iliuk, L. H. Hu and W. A. Tao, Anal. Chem., 2011, 83, 4440.

58 S. P. Song, Y. Qin, Y. He, Q. Huang, C. H. Fan and H. Y. Chen, Chem. Soc. Rev., 2010, 39, 4234.

B. Soontornworajit and Y. Wang, Anal. Bioanal. Chem., 2011, 399, 1591.

60

D. W. Drolet, L. Moon-McDermott and T. S. Romig, Nat. Biotechnol., 1996, 14, 1021.

R. Kirby, E. J. Cho, B. Gehrke, T. Bayer, Y. S. Park, D. P. Neikirk, J. T. McDevitt and A. D. Ellington, Anal. Chem., 2004, 76, 4066.

T. Kato, K. Yano, K. Ikebukuro and I. Karube, Analyst, 2000, 125, 1371.

Y. Li, H. J. Lee and R. M. Corn, Anal. Chem., 2007, 79, 1082.

C. A. Savran, S. M. Knudsen, A. D. Ellington and S. R. Manalis, Anal. Chem., 2004, 76, 3194.

L. H. Guo and D. H. Kim, Biosens. Bioelectron., 2012, 31, 567.

66

D. J. Anderson and G. Blobel, Meth. Enzymol., 1983, 96, 111.

V. Pavlov, Y. Xiao, B. Shlyahovsky and I. Willner, J. Am. Chem. Soc., 2004, 126, 11768.

C.-C. Huang, Y.-F. Huang, Z. Cao, W. Tan and H.-T. Chang, Anal. Chem., 2005, 77, 5735.

J. Zhou, B. Soontornworajit and Y. Wang, Biomacromolecules, 2010, 11, 2087.

J. Zhou, B. Soontornworajit, J. Martin, B. A. Sullenger, E. Gilboa and Y. Wang, Macromol. Biosci., 2009, 9, 831.

71 S. D. Jhaveri, R. Kirby, R. Conrad, E. J. Maglott, M. Bowser, R. T. Kennedy, G. Glick and A. D. Ellington, J. Am. Chem. Soc., 2000, 122, 2469.

H. Ueyama, M. Takagi and S. Takenaka, J. Am. Chem. Soc., 2002, 124, 14286.

73 M. N. Stojanovic, P. de Prada and D. W. Landry, J. Am. Chem. Soc., 2001, 123, 4928.

74 H. Urata, K. Nomura, S.-i. Wada and M. Akagi, Biochem. Biophys. Res. Comm., 2007, 360, 459. 

102, 17278.

76 J. Zhang, L. H. Wang, D. Pan, S. P. Song, F. Y. C. Boey, H. Zhang and C. H. Fan, Small, 2008, 4, 1196.

77 J. Wang, L. H. Wang, X. F. Liu, Z. Q. Liang, S. P. Song, W. X. Li, G. X. Li and C. H. Fan, Adv. Mater., 2007, 19, 3943.

78 R. Nutiu and Y. Li, J. Am. Chem. Soc., 2003, 125, 4771.

79 R. Nutiu and Y. Li, Chem. Eur. J, 2004, 10, 1868.

80 P. Lau and Y. Li, Springer Berlin Heidelberg, 2013, pp. 1.

81 W. C. Winkler and R. R. Breaker, Annu. Rev. Microbiol., 2005, 59, 487.

82 P. S. Lau, B. K. Coombes and Y. F. Li, Angew. Chem. Int. Ed., 2010, 49, 7938.

83 S. K. Desai and J. P. Gallivan, J. Am. Chem. Soc., 2004, 126, 13247.

84 S. Topp and J. P. Gallivan, J. Am. Chem. Soc., 2007, 129, 6807.

85 Y. Shen, W. Chiuman, J. D. Brennan and Y. Li, ChemBioChem, 2006, 7, 1343.

86 R. Y. Lai, K. W. Plaxco and A. J. Heeger, Anal. Chem., 2007, 79, 229.

87 Y. Xiao, B. D. Piorek, K. W. Plaxco and A. J. Heeger, J. Am. Chem. Soc., 2005, 127, 17990.

88 J. Liu, J. H. Lee and Y. Lu, Anal. Chem., 2007, 79, 4120.

89 J. W. Liu and Y. Lu, Angew. Chem. Int. Ed., 2006, 45, 90.

90 C. H. Lu, H. H. Yang, C. L. Zhu, X. Chen and G. N. Chen, Angew. Chem. Int. Ed., 2009, 48, 4785 .

91 R. Yamamoto, T. Baba and P. K. Kumar, Genes to cells, 2000, 5, 389.

92 M. N. Stojanovic, P. de Prada and D. W. Landry, J. Am. Chem. Soc., 2000, 122, 11547.

93 C. Wu, L. Yan, C. Wang, H. Lin, C. Wang, X. Chen and C. J. Yang, Biosens. Bioelectron., $2010,25,2232$. 
F. Li, J. Zhang, X. N. Cao, L. H. Wang, D. Li, S. P. Song, B. C. Ye and C. H. Fan, Analyst, 2009, 134, 1355.

95 N. Dave and J. Liu, Chem. Comm., 2012, 48, 3718.

96 A. D. Kent, N. G. Spiropulos and J. M. Heemstra, Anal. Chem., 2013, 85, 9916.

97 M. N. Stojanovic and D. M. Kolpashchikov, J. Am. Chem. Soc., 2004, 126, 9266.

98 J. R. Babendure, S. R. Adams and R. Y. Tsien, J. Am. Chem. Soc., 2003, 125, 14716.

99 M. Famulok, Nature, 2004, 430, 976.

100 G. Sook Bang, S. Cho, N. Lee, B.-R. Lee, J.-H. Kim and B.-G. Kim, Biosens. Bioelectron., 2013, 39, 44.

101 W. Xu and Y. Lu, Anal. Chem., 2009, 82, 574.

102 J. Liu and Y. Lu, Adv. Mater., 2006, 18, 1667.

103 T. Bing, X. Liu, X. Cheng, Z. Cao and D. Shangguan, Biosens. Bioelectron., 2010, $25,1487$.

104 B. R. Baker, R. Y. Lai, M. S. Wood, E. H. Doctor, A. J. Heeger and K. W. Plaxco, J. Am. Chem. Soc., 2006, 128, 3138.

105 X. Zuo, Y. Xiao and K. W. Plaxco, J. Am. Chem. Soc., 2009, 131, 6944.

106 M. V. Yigit, D. Mazumdar, H.-K. Kim, J. H. Lee, B. Odintsov and Y. Lu, ChemBioChem, 2007, 8, 1675.

107 K. Zhang, M. Xie, B. Zhou, Y. Hua, Z. Yan, H. Liu, L.-n. Guo, B. Wu and B. Huang, Biosens. Bioelectron., 2013, 41, 123.

108 D.-W. Huang, C.-G. Niu, G.-M. Zeng and M. Ruan, Biosens. Bioelectron., 2011, 29, 178.

109 L.-L. Li, P. Ge, P. R. Selvin and Y. Lu, Anal. Chem., 2012, 84, 7852.

110 L. Wang, R. Yan, Z. Huo, L. Wang, J. Zeng, J. Bao, X. Wang, Q. Peng and Y. Li, Angew. Chem., Int. Ed., 2005, 44, 6054.

111 F. Wang and X. Liu, Chem. Soc. Rev., 2009, 38, 976.

112 L.-L. Li, P. Wu, K. Hwang and Y. Lu, J. Am. Chem. Soc., 2013, 135, 2411. 
113 L.-L. Li, R. Zhang, L. Yin, K. Zheng, W. Qin, P. R. Selvin and Y. Lu, Angew. Chem., Int. Ed., 2012, 51, 6121.

114 M. Wang, W. Hou, C.-C. Mi, W.-X. Wang, Z.-R. Xu, H.-H. Teng, C.-B. Mao and S.-K. Xu, Anal. Chem., 2009, 81, 8783.

115 Z. Chen, H. Chen, H. Hu, M. Yu, F. Li, Q. Zhang, Z. Zhou, T. Yi and C. Huang, J. Am. Chem. Soc., 2008, 130, 3023.

116 M. Kumar and P. Zhang, Biosens. Bioelectron., 2010, 25, 2431.

117 Y. Wang, L. Bao, Z. Liu and D.-W. Pang, Anal. Chem., 2011, 83, 8130.

118 F. B. Lin, B. D. Yin, C. Z. Li, J. H. Deng, X. Y. Fan, Y. H. Yi, C. Liu, H. T. Li, Y. Y. Zhang and S. Z. Yao, Anal. Methods, 2013, 5, 699.

119 M. V. Yigit, D. Mazumdar and Y. Lu, Bioconjug. Chem., 2008, 19, 412.

120 D. W. Hwang, H. Y. Ko, J. H. Lee, H. Kang, S. H. Ryu, I. C. Song, D. S. Lee and S. Kim, Journal of Nuclear Medicine, 2010, 51, 98.

121 H. Hu, A. T. Dai, J. Sun, X. Y. Li, F. H. Gao, L. Z. Wu, Y. Fang, H. Yang, L. An, H. X. Wu and S. P. Yang, Nanoscale, 2013, 5, 10447.

122 M. K. Yu, D. Kim, I. H. Lee, J. S. So, Y. Y. Jeong and S. Jon, Small, 2011, 7, 2241.

123 W. Xu and Y. Lu, Chem. Comm., 2011, 47, 4998.

124 D. S. Seferos, D. A. Giljohann, H. D. Hill, A. E. Prigodich and C. A. Mirkin, J. Am. Chem. Soc., 2007, 129, 15477.

125 A. E. Prigodich, D. S. Seferos, M. D. Massich, D. A. Giljohann, B. C. Lane and C. A. Mirkin, ACS Nano, 2009, 3, 2147.

126 B. Dubertret, M. Calame and A. J. Libchaber, Nat. Biotechnol., 2001, 19, 365.

127 C. S. Yun, A. Javier, T. Jennings, M. Fisher, S. Hira, S. Peterson, B. Hopkins, N. O. Reich and G. F. Strouse, J. Am. Chem. Soc., 2005, 127, 3115. 
128 D. S. Seferos, A. E. Prigodich, D. A. Giljohann, P. C. Patel and C. A. Mirkin, Nano Lett., 2009, 9, 308 .

129 D. Zheng, D. S. Seferos, D. A. Giljohann, P. C. Patel and C. A. Mirkin, Nano Lett., 2009, 9, 3258.

130 S. P. Song, Z. Q. Liang, J. Zhang, L. H. Wang, G. X. Li and C. H. Fan, Angew. Chem. Int. Ed., 2009, 48, 8670 .

131 A. E. Prigodich, P. S. Randeria, W. E. Briley, N. J. Kim, W. L. Daniel, D. A. Giljohann and C. A. Mirkin, Anal. Chem., 2012, 84, 2062.

132 N. Li, C. Chang, W. Pan and B. Tang, Angew. Chem., Int. Ed., 2012, 51, 7426.

133 M. S. L. Raddatz, A. Dolf, E. Endl, P. Knolle, M. Famulok and G. Mayer, Angew. Chem. Int. Ed., 2008, 47, 5190.

134 P. J. J. Huang and J. W. Liu, Anal. Chem., 2010, 82, 4020.

135 D. Shangguan, Y. Li, Z. Tang, Z. C. Cao, H. W. Chen, P. Mallikaratchy, K. Sefah, C. J. Yang and W. Tan, Proc. Natl. Acad. Sci. U.S.A., 2006, 103, 11838.

136 J. K. Herr, J. E. Smith, C. D. Medley, D. Shangguan and W. Tan, Anal. Chem., 2006, 78, 2918.

137 Y. Xu, J. A. Phillips, J. L. Yan, Q. G. Li, Z. H. Fan and W. H. Tan, Anal. Chem., 2009, 81, 7436.

138 X. Zuo, S. Song, J. Zhang, D. Pan, L. Wang and C. Fan, J. Am. Chem. Soc., 2007, 129, 1042.

139 Y. Xiao, A. A. Rowe and K. W. Plaxco, J. Am. Chem. Soc., 2007, 129, 262.

140 J. S. Swensen, Y. Xiao, B. S. Ferguson, A. A. Lubin, R. Y. Lai, A. J. Heeger, K. W. Plaxco and H. T. Soh, J. Am. Chem. Soc., 2009, 131, 4262.

141 S. J. Guo and S. J. Dong, Trac-Trend. Anal. Chem., 2009, 28, 96.

142 Y. Xiao, A. A. Lubin, A. J. Heeger and K. W. Plaxco, Angew. Chem., Int. Ed., 2005, 44, 5456.

143 A. A. Rowe, E. A. Miller and K. W. Plaxco, Anal. Chem., 2010, 82, 7090.

144 Y. Xiang and Y. Lu, Nat. Chem., 2011, 3, 697. 
145 L. Yan, Z. Zhu, Y. Zou, Y. Huang, D. Liu, S. Jia, D. Xu, M. Wu, Y. Zhou, S. Zhou and C. J. Yang, J. Am. Chem. Soc., 2013, 135, 3748.

146 J. Liu, D. Mazumdar and Y. Lu, Angew. Chem., Int. Ed., 2006, 45, 7955.

147 H. Xu, X. Mao, Q. Zeng, S. Wang, A.-N. Kawde and G. Liu, Anal. Chem., 2008, 81, 669.

148 R. Pelton, Trac-Trend. Anal. Chem., 2009, 28, 925.

149 M. M. Ali, S. D. Aguirre, Y. Q. Xu, C. D. M. Filipe, R. Pelton and Y. F. Li, Chem. Comm., $2009,6640$.

150 S. M. Z. Hossain, R. E. Luckham, A. M. Smith, J. M. Lebert, L. M. Davies, R. H. Pelton, C. D. M. Filipe and J. D. Brennan, Anal. Chem., 2009, 81, 5474.

151 M. N. Stojanovic and D. W. Landry, J. Am. Chem. Soc., 2002, 124, 9678.

152 P. Travascio, Y. Li and D. Sen, Chem. Biol., 1998, 5, 505.

153 T. Niazov, V. Pavlov, Y. Xiao, R. Gill and I. Willner, Nano Lett., 2004, 4, 1683.

154 Y. Weizmann, M. K. Beissenhirtz, Z. Cheglakov, R. Nowarski, M. Kotler and I. Willner, Angew. Chem., Int. Ed., 2006, 45, 7384.

155 C. Yang, V. Lates, B. Prieto-Simon, J.-L. Marty and X. Yang, Biosens. Bioelectron., 2012, 32, 208.

156 S. Scarano, M. Mascini, A. P. F. Turner and M. Minunni, Biosens. Bioelectron., 2010, $25,957$.

157 M. J. Kwon, J. Lee, A. W. Wark and H. J. Lee, Anal. Chem., 2012, 84, 1702.

158 N. H. Kim, S. J. Lee and M. Moskovits, Nano Lett., 2010, 10, 4181.

159 E. Baldrich, A. Restrepo and C. K. O'Sullivan, Anal. Chem., 2004, 76, 7053.

160 D. Xu, D. Xu, X. Yu, Z. Liu, W. He and Z. Ma, Anal. Chem., 2005, 77, 5107.

161 D. M. Mishler, S. Topp, C. M. K. Reynoso and J. P. Gallivan, Curr. Opin. Biotechnol., 2010, 21, 653.

162 C. C. Fowler, E. D. Brown and Y. F. Li, Chem. Biol., 2010, 17, 756.

163 J. Sinha, S. J. Reyes and J. P. Gallivan, Nat. Chem. Biol., 2010, 6, 464. 
164 C. Carrasquilla, P. S. Lau, Y. Li and J. D. Brennan, J. Am. Chem. Soc., 2012, 134, 10998.

165 M. Y. Li, N. Lin, Z. Huang, L. P. Du, C. Altier, H. Fang and B. H. Wang, J. Am. Chem. Soc., 2008, 130, 12636.

166 H. H. Yang, H. P. Liu, H. Z. Kang and W. H. Tan, J. Am. Chem. Soc., 2008, 130, 6320.

167 N. Dave, P.-J. J. Huang, M. Y. Chan, B. D. Smith and J. Liu, J. Am. Chem. Soc., 2010, 132, 12668.

168 Y. Xing, E. Cheng, Y. Yang, P. Chen, T. Zhang, Y. Sun, Z. Yang and D. Liu, Adv. Mater., 2011, 23, 1117 .

169 B. Soontornworajit, J. Zhou and Y. Wang, Soft Matter, 2010, 6, 4255.

170 J. Liu, Phys. Chem. Chem. Phys., 2012, 14, 10485.

171 M. Levy, S. F. Cater and A. D. Ellington, ChemBioChem, 2005, 6, 2163.

172 J. A. Hansen, R. Mukhopadhyay, J. O. Hansen and K. V. Gothelf, J. Am. Chem. Soc., 2006, 128, 3860.

173 J. A. Hansen, J. Wang, A.-N. Kawde, Y. Xiang, K. V. Gothelf and G. Collins, J. Am. Chem. Soc., 2006, 128, 2228.

174 C. Teller and I. Willner, Curr. Opin. Biotechnol., 2010, 21, 376.

175 Y. Weizmann, Z. Cheglakov and I. Willner, J. Am. Chem. Soc., 2008, 130, 17224.

176 B. Shlyahovsky, D. Li, Y. Weizmann, R. Nowarski, M. Kotler and I. Willner, J. Am. Chem. Soc., 2007, 129, 3814.

177 L. T. Yang and A. D. Ellington, Anal. Biochem., 2008, 380, 164.

178 W. Zhao, M. M. Ali, M. A. Brook and Y. Li, Angew. Chem., Int. Ed., 2008, 47, 6330.

179 H. Zhang, F. Li, X.-F. Li and X. C. Le, Methods, 2013, 64, 322.

180 D. A. Di Giusto, W. A. Wlassoff, J. J. Gooding, B. A. Messerle and G. C. King, Nucleic Acids Res., 2005, 33, e64/1. 
181 H. Zhang, F. Li, B. Dever, C. Wang, X.-F. Li and X. C. Le, Angew. Chem., Int. Ed., 2013, 52, 10698.

182 H. Zhang, X.-F. Li and X. C. Le, Anal. Chem., 2013, 84, 877. 